\title{
HPV Prevalence Rates among 18-60-Year-Old Women with Normal Pap Smear Visiting Gynaecology Clinics in Isfahan University of Medical Sciences
}

\author{
Tajossadat Allameh, Farinaz Farahbod, Sharare Moghim and Zahra Allameh* \\ Faculty of Medicine, Department of Obstetrics and Gynecology, Isfahan University of Medical Sciences, Isfahan, Iran
}

\begin{abstract}
Cervical cancer is the fourth most common cancer that occurs in women worldwide. In 2012 there were about 530,000 new cases reported of which about 270,000 were fatal. The fraction of these deaths that could be attributed to Human Papilloma Virus (HPV) was estimated to be 100 percent. Since the high-risk HPV virus causes cervical cancer, it is necessary to screen the population and eventually vaccinate against HPV. This is a descriptive crosssectional study conducted on 355 eighteen-to-sixty-year-old married women with normal Pap smear who visited the OB/GYN clinics of Isfahan University of Medical Sciences. Specimens from cervix transformation zone and endocervical canal were obtained by cytobrush method; then cytology study was performed on them, DNA being extracted. The presence of HPV infection and its subtypes including HPV 16, 18, 6, and 11 were assessed by using polymerase chain reaction method. Ninety cases $(25.35 \%$ of the cases) had positive HPV PCR. Among these positive samples, $15.56 \%$ were type $16 ; 13.33 \%$ were type $18 ; 21.11 \%$ were type 11 or 6 , and $50 \%$ were of other types. Of all positive cases, $7.22 \%$ were carrying at least one of the high-risk type of the virus. Based on the high prevalence of this virus in this as well as other studies, it was specifically proven that types 16 and 18 are risk factors for premalignant and malignant lesions of cervix. Moreover, administration of Quadrivalent vaccine in prevention of cervical cancer is suggested for our population.
\end{abstract}

Keywords: Pap smear; Human papilloma viruses; Cervical cancer; PCR

\begin{abstract}
Abbreviations: PCR: Polymerase Chain Reaction; DNA: Deoxyribonucleic Acid; RRR: Relative Risk Reduction, HPV: Human Papilloma Virus; PCO/PCO3: Oligonucleotides, Primers Used to Amplify the $\beta$-globulin Gene; GP5+/6+: General Primers; GP5+/ GP6+: Modified PCR Methods are Frequently Used for Detection of HPV; ACIP: Advisory Committee on Immunization Practices; VAERS: Vaccine Adverse Event Reporting System
\end{abstract}

\section{Introduction}

As of 2017, the world population of women aged 15 or older who are at the risk of developing cervical cancer has been estimated to be 2,784 million [1]. The estimated cervical cancer incidence in US Canada, Australia, most of Europe, China and middle East, is lowest, (less than 7.9 per 100,000) while some other countries located in the southern part of Africa have the highest rate [1]. The mortality rate, similarly is lowest in countries such as Canada, Australia, most of Europe, and Middle East. The mortality rate is less than $1 / 3$ of affected women in these countries, however, more than half of women affected with cervical cancer die in some parts of Africa [1]. According to an article published in 2017, the USA Centers for Disease Control and Prevention, reported the most common sexually transmitted diseases in the US remains to be HPV infection [2]. The fourth most common cancer among women worldwide and $2^{\text {nd }}$ among women aged between 15 and 44 worldwide is cancer of cervix uteri [3]. A study conducted in USA during the 2013-2014 period found that 4 out of 10 people ages 1859 had genital HPV infection [2]. In 2012, the number of reported new cases of cervical cancer reached 527,624 and number of related deaths was reported to be 265,672 . It is estimated that $100 \%$ of such deaths are attributable to HPV $[4,5]$. About $80 \%$ of the worldwide mortalities belong to third-world countries. It is estimated that this percentage will rise to $90 \%$ in 2020 [5]. Also 54\% of new reported deaths occur in Asian countries [3]. According to National Cancer Institute, the number of new cases of cervix cancer among women, averaged over the 2007-2013 was reported to be 7.4 per 100,000 per year [6]. Based on the 2012-2014 data, about $0.6 \%$ of women will be diagnosed with cervix uteri cancer at some point during their lifetime [6]. The occurrence and prevalence of mortality related to this cancer has decreased by $70 \%$ relative risk reduction (RRR) over the last 50 years. This has been credited to routine Pap smear screening. Recently, multiple risk factors have been reported for causing and/or progression of cervical cancer for which HPV is the most known common risk factor [7]. Since HPV is a DNA virus, its typing and characterization has been facilitated by DNA sequencing [8]. HPV virus, with inhibition apoptosis (planned cellular death) and with production of inhibitor proteins of P53 and retinoblastoma genes, leads to the accumulation of cancer cells into tumors [9-12]. More than 40 species of HPV virus, with ability to infect genital areas, have been recognized. Of these about 15 are carcinogens, with the capability to cause cervical cancer and premalignant lesions such as CIN III. Types 16 and 18 of HPV virus are the most common cause of cervical cancer. Type 16 has been responsible for $60 \%$ of the occurrences, while type 18 has been seen in only $10 \%$ to $20 \%$ of such cancers [13]. Interestingly, HPV has been detected in $30 \%$ of oropharynx cancers, $45 \%$ to $95 \%$ of anal cancers, $60 \%$ to $65 \%$ of the vaginal cancers, and $40 \%$ to $60 \%$ of

*Corresponding author: Zahra Allameh, Associate Professor, Faculty of Medicine, Department of Obstetrics and Gynecology, Isfahan University of Medical Sciences, Isfahan, Iran, Tel: 989133159672; E-mail: z_allameh@med.mui.ac.ir

Received September 28, 2017; Accepted November 27, 2017; Published November 28, 2017

Citation: Allameh T, Farahbod F, Moghim S, Allameh Z (2017) HPV Prevalence Rates among 18-60-Year-Old Women with Normal Pap Smear Visiting Gynaecology Clinics in Isfahan University of Medical Sciences. J Cancer Sci Ther 9: 723-726. doi:10.4172/1948-5956.1000498

Copyright: ( 2017 Allameh T, et al. This is an open-access article distributed under the terms of the Creative Commons Attribution License, which permits unrestricted use, distribution, and reproduction in any medium, provided the original author and source are credited. 
vulvar cancers $[14,15]$. Specific PCR is a simple, economic method in detecting each type of HPV [16]. Although Types 16, 18, 31, 33 of HPV are known as the most common cancerous types in the world, they are not the most common reported [16]. Therefore, it seems necessary to detect the most common type of HPV in each population separately. In this regard, a screening method can be developed for the population and eventually provide an appropriate vaccination for that same population. In order to achieve this goal, different types of the HPV namely: 6, 11, 16, and 18 were investigated with normal Pap smear among 18-60-years-old married women who visited ob/gyn clinics affiliated with the Isfahan University of Medical Sciences between 2009 and 2010. The data obtained are shared here without personal identifiers as aggregate, so the privacy of the patients is protected.

\section{Materials and Methods}

This is a descriptive cross-sectional study conducted on 355 of the aforementioned 18-60-year-old patients with normal Pap smear (Conventional method). All women were examined clinically by a gynecologist and for each case a new cervical smear was prepared using a plastic Ayer spatula and an endocervical brush. A second specimen of epithelial cells from transformation zone and endocervix was prepared using a $360^{\circ}$ sweep of nylon cytobrush. The collected specimens were placed in sterile tubes containing $5 \mathrm{cc}$ phosphate buffer saline, stored at $-70^{\circ} \mathrm{C}$ for HPV molecular analysis. The DNA extraction from epithelial cells was conducted using the standard phenol-chloroform and the ethanol precipitation method. The extracted DNA was then stored at $-20^{\circ} \mathrm{C}$ until tested for HPV subtypes (HPV subtypes 16,18 and 6 or 11) by PCR method. For quality control of DNA extraction from specimens, $\beta$-globin gene PCR was done using PCO3/PCO4 primers, leading to the amplification of $110 \mathrm{bp}$ segments of the $\beta$-globin gene, according to the previously described procedures $[17,18]$. The detection of HPV in the specimens was done with GP5+ and GP6+primers in a PCR assay. HPV-DNA detection was performed by a standard GP5+GP6+PCRbased assay, which allows for detection of a broad spectrum of genital HPV types.

\section{Results}

The results of the first step of PCR from the 355 tests conducted are presented in Table 1. They indicate the presence of HPV viruses in $25.35 \%$ of the cases. The frequency distribution of each type of HPV virus in Pap smears is shown in Figure 1. Consistent with the fact that Types 16 and 18 have been reported as high-risk, one of these types was found in $7.32 \%$ of the samples ( 26 out of 355 cases studied here). Half of the positive cases ( 45 out of 90 ) showed HPV types other than 16 and 18 . These cases were not included in this study.

\section{Discussion}

According to the results of this study, out of 355, 90 samples (25.35\%) were positive for HPV, 28.88\% of which were Types 16 and 18. Types 16 and 18 were found in $7.32 \%$ of all cases. A total of 19 cases $(21.11 \%$ of 90 positive samples) were Type 6 or 11 . Therefore, the prevalence of Type 6 or 11 was 5.35\% in normal Pap smears. While HPV Types 16 and 18 are known to be high risk, HPV Types 6 and

\begin{tabular}{|c|c|c|c|}
\hline Virus type & No. of Samples & \% Total & \% positive \\
\hline Type 18 & 12 & 3.38 & 13.33 \\
\hline Type 16 & 14 & 3.94 & 15.56 \\
\hline Type 6 or 11 & 19 & 5.35 & 21.11 \\
\hline Other Types & 45 & 12.68 & 50.00 \\
\hline
\end{tabular}

Table 1: Results of PCR: Fraction of HPV virus types.

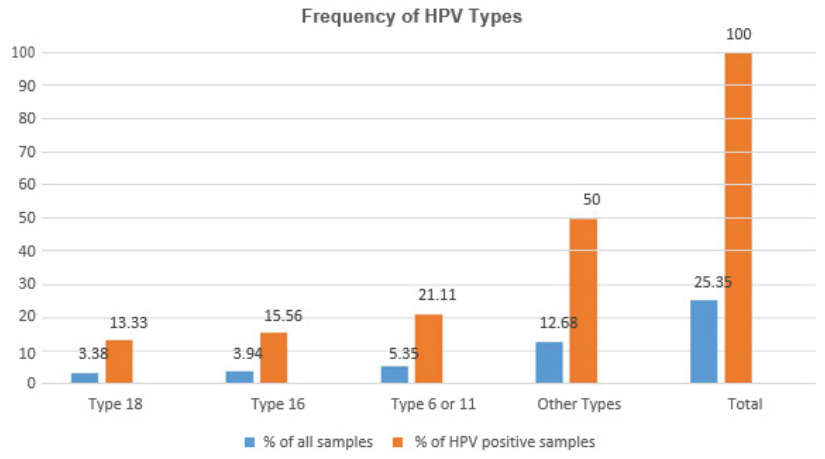

Figure 1: Frequency distribution of HPV virus types in normal Pap smear samples.

11 are the low risk types causing genital warts. About $60 \%$ of cervical cancers are associated with Type 16 and $10 \%$ to $20 \%$ are associated with Type 18 [12]. In this study, the prevalence of HPV was found to be more common compared to other studies. Kjaer et al. [19] studied the prevalence of this virus among the 1,000 women with normal Pap smear in Denmark. They found that 147 of the samples showed DNA of HPV. Among these samples, 108 cases (73.5\%) were found to be related to the high-risk types, and 41 of them to the low risk types. In comparison to the results presented here, Kjaer et al. reported a stronger relationship between cervical cancer and the high-risk virus types. This may be due to the consideration of 14 types as high-risk by these authors. In another study, Rozen Daal et al. [20] reported the prevalence of HPV virus in 1622 females with normal Pap smear to be $6 \%$. Among the HPV positive cases, $67.3 \%$ belonged to Types 16 , 18 and 31 (considered as high-risk types). In contrast, only 3 samples (3.1\%) were found to be of low-risk types $(6,11)$. Sherpa et al. studied Nepali women with normal Pap smear tests and found the prevalence of virus to be $8.6 \%$. The prevalence of high risk types was reported as $6.1 \%$ [21] Many Iranian studies [22-25] evaluating prevalence of HPV in women with cervical cancer in different provinces reported varying results. Allameh et al. [26] investigated the prevalence of this virus in patients with intra epithelial neoplasia and cervical cancer, the prevalence of HPV virus was 90.8\%, 49.1\% of which were Types 16 and 18 , and $22 \%$ were types 6 and 11 . In our study, at least $50 \%$ of types were one of these 4 types. Recently vaccination by Quadrivalent or 9-Valent HPV is recommended to prevent HPV infection and related cancers [26-29]. One study [30] has reported the efficacy of this vaccine to be $90 \%$ in prevention of HPV infection and $100 \%$ in prevention of cervical lesions. The study was performed on women aged between 15 and 25 who received at least 3 doses of this vaccine over a period of 36 months. Cervical cancer is very common with a high mortality rate. Fortunately, it can be prevented by screening in early stages of the disease. Pap smear is one of the very primitive and common methods of screening for cervical cancer. The USA Centers for Disease Control and Prevention recommends vaccination against HPV infection as well as HPV related cancer [31,32]. The United States Advisory Committee on Immunization Practices (ACIP) recommends HPV vaccination for females aged 11 to 12 for the prevention of cervical, vaginal, and vulvar cancer and the related precursor lesions caused by the HPV types targeted by these vaccines [27-30]. From 2006 to 2013, Vaccine Adverse Effect Reporting System (VAERS) received 21,194 reports of adverse events following HPV immunization among female [33]. On the other hand, there are many studies who found the Quadrivalent vaccine to be generally safe [34-36] 
Citation: Allameh T, Farahbod F, Moghim S, Allameh Z (2017) HPV Prevalence Rates among 18-60-Year-Old Women with Normal Pap Smear Visiting Gynaecology Clinics in Isfahan University of Medical Sciences. J Cancer Sci Ther 9: 723-726. doi:10.4172/1948-5956.1000498

\section{Conclusion}

A study of prevalence of HPV was conducted on 355 women visiting gynecology clinics of Isfahan University of Medical Sciences. The results show:

1. About $25 \%$ of all cases showed infection with HPV.

2. Of the infected cases, nearly half were of Type $16,18,6$ or 11 .

3. Types 16 and 18 were the most common.

4. About half of the cases infected by HPV were other types

5. The administration of HPV vaccine is highly recommended as primary prevention of cervical cancer.

\section{Acknowledgments}

The authors acknowledge the institutional support of the administration and staff of the IUMS University under Project \# 389140. Thanks go to Prof. Janghorban of the University of Medical Sciences of Isfahan, Iran, for his careful review of the manuscript and for his helpful suggestions.

\section{Author Contributions}

The investigation and reported conducted in this study was contributed as follows: "T.A. conceived and guided the work; Z.A. performed the operations; F.F. and S.M. helped with data collection and analysis. T.A. and Z.A. contributed to the writing of the paper.

\section{References}

1. Bruni L, Barrionuevo-Rosas L, Albero G, Serrano B, Mena M, et al. (2017) ico information centre on HPV and cancer (HPV Information Centre). Human papillomavirus and related diseases in the world.

2. Mohney $G$ (2017) Men have higher rates of HPV than women, CDC says. ABC News, USA.

3. Ferlay J, Soerjomataram I, Ervik M, Dikshit R, Eser S, et al. (2013) Cancer prevalence and mortality worldwide, GLOBOCAN 20121.2, IARC Cancer Base No. 11 Lyon, France.

4. Forman D, De Martel C, Lacey CJ, Soerjomataram I, Lortet-Tieulent J et al. (2012) Global burden of human papillomavirus and related diseases 30: F12-23.

5. Parkin DM, Bray F, Ferlay J, Pisani P (2005) Global cancer statistics, 2002. CA Cancer J Clin 55: 74-108.

6. Cancer stat facts (2017) Cervix uteri cancer, National Institute of Health, National Cancer Institute, Bethesda, MD, surveillance, epidemiology, and end results program, SEER cancer statistics review (CSR) 175-2014.

7. Kufe DW, Pollock RE, Weichselbaum RR, Gansler, TS (2003) Holland-Frei III, E. cancer medicine, 6th ed., BC Decker Inc., Hamilton, Canada.

8. Tilston P (1997) Anal human papillomavirus and anal cancer. J Clin Pathol 50: 625-634.

9. Behtash N, Mousavi A, Mohit M, Modares M, Khanafshar N (2003) Simple hysterectomy in the presence of invasive cervical cancer in Iran.Int J Gyneco Cancer 13: 177-181.

10. Behtash N, Mousavi A, Tehranian A, Khanafshar N, Hanjani P (2003) Embryonal, rhabdomyosarcoma of the uterine cervix: Case report and review of the literature. Gynecol Oncol 91: 452-455.

11. De Sanjose S, Quint WG, Alemany L, Geraets DT, Klaustermeier JE, et al. (2010) Human papillomavirus genotype attribution in invasive cervical cancer: a retrospective cross-sectional worldwide study. Lancet Oncol 11: 1048-1056.

12. Behtash N, Ghaemmaghami F, Yarandi F, Ardalan FA, Khanafshar N (2002) Cutaneous metastasis from carcinoma of the cervix at the drain site. Gynecol Oncol 85: 209-211.

13. Muñoz N, Bosch FX, De Sanjosé S, Herrero R, Castellsagué X (2003) Epidemiologic classification of human papillomavirus types associated with cervical cancer. N Engl J Med 348: 518-527.

14. Daling JR, Madeleine MM, Johnson LG, Schwartz SM, Shera KA (2004) Human papillomavirus, smoking, and sexual practices in the etiology of anal cancer. Cancer. 101: 270-280.
15. Schiffman M, Kjaer SK (2003) Natural history of anogenital human papillomavirus infection and neoplasia.J J Natl Cancer Inst Monogr 14-19.

16. Walboomers JM, Jacobs MV, Manos MM, Bosch FX, Kummer JA (1999) Human papillomavirus is a necessary cause of invasive cervical cancer worldwide. $J$ Pathol 189: 12-19.

17. Hamkar R, Azad TM, Mahmoodi M, Seyedirashti S, Severini A (2002) Prevalence of human papillomavirus in Mazandaran Province, Islamic Republic of Iran. East Mediterr Health J 8: 805-811.

18. Hamkar R, Azad TM, Mahmoodi M, Seyedirashti S, Severini A (2002) Prevalence of various types of HPV among cervical cancer and normal biopsy in north of Iran. Iranian J Infect Dis Trop Med 8: 9-15.

19. Kjaer SK, Van Den Brule AJ, Bock JE, Poll PA, Engholm G (1997) Determinants for genital human papillomavirus (HPV) infection in 1000 randomly chosen young Danish women with normal Pap smear: Are there different risk profiles for oncogenic and nononcogenic HPV types? Cancer Epidemiol Biomarkers Prev 6: 799-805

20. Rozendaal L, Walboomers JM, Van Der Linden JC, Voorhorst FJ, Kenemans $P$ et al. (1996) PCR-based high-risk HPV test in cervical cancer screening gives objective risk assessment of women with cytomorphologically normal cervical smears. Int J Cancer 68: 766-769.

21. Sherpa AT, Clifford GM, Vaccarella S, Shrestha S, Nygård M (2009) Human papillomavirus infection in women with and without cervical cancer in Nepal. Cancer Causes Control 21: 323-330.

22. Mortazavi S, Zali M, Raoufi M, Nadji M, Kowsarian P (2002) The prevalence of human papillomavirus in cervical cancer in Iran. Asian Pac J Cancer Prev 3: 69-72.

23. Sadeghi A, Sobhani A, Etaati Z, Jahanlu A, Shiroodi M (2008) Prevalence of human papilloma virus among women with cervical intraepithelial neoplasia II and invasive cervical cancer from 2001-2006 in Bandarabas. Iranian J Pathol 3: 183-185.

24. Ghaffari SR, Sabokbar T, Mollahajian H, Dastan J, Ramezanzadeh F (2006) Prevalence of human papillomavirus genotypes in women with normal and abnormal cervical cytology in Iran. Asian Pac J Cancer Prev 7: 529-532.

25. Niakan, M, Yarandi, F, Entezar M (2009) Human papilloma virus (HPV) detection in biopsies from cervical cancer patients; A population based study from Iran. Iranian J Clin Infect Dis 4: 35-37.

26. Allameh T, Moghim S, Asadi-Zeidabadi M (2011) A survey on the prevalence of high-risk subtypes of human papilloma virus among women with cervical neoplasia in Isfahan University of Medical Science. Arch Gynecol Obstet 284 1509-1513.

27. Kim DK, Bridges CB, Harriman KH (2016) Advisory committee on immunization practices recommended immunization schedule for adults Aged 19 years or older: United States. Ann Intern Med 164: 184.

28. Markowitz LE, Dunne EF, Saraiya M, Chesson HW, Curtis CR, et al. (2014) Human papillomavirus vaccination: Recommendations of the Advisory Committee on Immunization Practices (ACIP). MMWR Recomm Rep 63: 1-30.

29. Petrosky E, Bocchini JA Jr, Hariri S, Chesson H, Curtis CR (2015) Use of 9-valent human papillomavirus (HPV) vaccine: Updated HPV vaccination recommendations of the advisory committee on immunization practices. Morb Mortal Wkly Rep 64: 300-304.

30. Robinson CL, Romero JR, Kempe A, Pellegrini C (2017) Advisory committee on immunization practices recommended immunization schedule for children and adolescents aged 18 years or younger-United States, 2017. Am J Transplant 17: $1136-1138$

31. Bayas JM, Costas L, Muñoz A (2008) Cervical cancer vaccination indications, efficacy, and side effects. Gynecol Oncol 110: S11-14.

32. Meites E, Kempe A, Markowitz LE (2017) Use of a 2-dose schedule for human papillomavirus vaccination-updated recommendations of the advisory committee on immunization practices. MMWR Morb Mortal Wkly Rep 65: 1405-1408.

33. Arnheim-Dahlström L, Pasternak B, Svanström H, Sparén P, Hviid A (2013) Autoimmune, neurological, and venous thromboembolic adverse events after immunisation of adolescent girls with quadrivalent human papillomavirus vaccine in Denmark and Sweden: Cohort study. BMJ 347: f5906.

34. Kim JJ (2010) Targeted human papillomavirus vaccination of men who have sex with men in the USA: a cost-effectiveness modelling analysis. Lancet Infect Dis 10: $845-852$ 
Citation: Allameh T, Farahbod F, Moghim S, Allameh Z (2017) HPV Prevalence Rates among 18-60-Year-Old Women with Normal Pap Smear Visiting Gynaecology Clinics in Isfahan University of Medical Sciences. J Cancer Sci Ther 9: 723-726. doi:10.4172/1948-5956.1000498

35. Scheller NM, Pasternak B, Svanström H, Hviid A (2014) Quadrivalent human papillomavirus vaccine and the risk of venous thromboembolism. JAMA 312 : 187-188.
36. Brotherton JM, Gold MS, Kemp AS, Mclntyre PB, Burgess MA (2008) Anaphylaxis following quadrivalent human papillomavirus vaccination. CMAJ 179: 525-533. 